\title{
PERSONAL PERSPECTIVE IN TV NEWS INTERVIEWS
}

\author{
Jennifer Alber, Daniel O'Connell and Sabine Kowal
}

\begin{abstract}
Two interviews by Christiane Amanpour televized September 8, 2000 on CNN, one with Ehud Barak and one with Yasser Arafat were analyzed for indicators of personal perspective. Generally, use of the same indicators as in Suleiman, O'Connell, \& Kowal (2002) was confirmed: Number of syllables spoken; use of first-person singular and plural pronominals and second-person pronominals; hesitations; smooth and interruptive turn transitions; and questions posed by interviewees. The interview with Arafat was extraordinarily agonistic, as manifested in his excessive use of first-person singular and second-person pronominals, hesitations, questions, and interruptions. For her part, Amanpour incited the shift to agonism with her provocative questioning. She then moved toward a more personal perspective by speaking proportionally more and by using more first-person singular pronominals and hesitations, all the while still maintaining her professional style of smooth turn transition. The dialogical character of personal perspective is discussed.
\end{abstract}

Keywords: Perspective, TV news interviews, dialogue.

\section{Theoretical background}

A comprehensive concept of personal perspective had already made its appearance in modern psychology in the writings of William James $(1890 / 1983 ; 380 \mathrm{f}$.) in the context of attention:

\footnotetext{
"My experience is what I agree to attend to. Only those items which I notice shape my mind without selective interest, experience is an utter chaos. Interest alone gives accent and emphasis, light and shade, background and foreground - intelligible perspective, in a word. It varies in every creature, but without it the consciousness of every creature would be a gray chaotic indiscriminateness, impossible for us even to conceive."
}

The quotation from James makes it clear that perspective for him was something that an individual has in relation to external reality. The complexity and individuality of personal perspective have in the meantime kept it from center stage as a topic of research in language use. Yet it remains of central importance, particularly since the personal perspectives of both speaker and listener affect all verbal interaction: Every human communicative situation involves some form of "attunemient to the attunement of the other" (Barwise \& Perry 1983, as cited in Linell 1998: 114).

Quite different is the concept of perspective taking. From the point of view of a 
social psychologist, Holtgraves (2002: 121) has recently described the process of perspective taking as follows:

"In order to construct an utterance that will be understood by a recipient, the speaker must try to
adopt the hearer's perspective, to see the world (roughly) the way the hearer sees it, and to formulate
the remark with that perspective in mind."

He then lists many theorists who "have argued that it is the fundamental task in language use (Brown 1965; Clark 1985; Krauss and Fussell 19991a, 1991b; Mead 1934; Rommetveit 1974)" and in the same context makes Clark's (1996) insistence that "it is coordination that is the essence of successful communication" (Holtgraves 2002: 122) well nigh synonymous with perspective taking. These generalizations appear somewhat exaggerated. Holtgraves' (121) assertion that "the speaker must try to adopt the hearer's perspective" is the locus of the exaggeration. Webster's (1983:58) provides the following relevant dictionary meanings of adopt: "To take up and practice or use as one's own. . . to accept formally and put into effect". Now this is precisely what one does not do in order to communicate effectively with a listener: One does not need to adopt the listener's perspective, but does indeed need to take it into account and make use of it. For example, one does not need to adopt a student's perspective in order to reply to a question, but one certainly must take the student's perspective into account. There is a vast difference between the two concepts of adopting and taking into account. Were adoption of another's perspective really necessary, few of us would ever communicate anything to anyone. Nor is coordination the essence of successful communication, only a prerequisite for it (see Rommetveit 1974: 52); one can be completely coordinated with an interlocutor and fail miserably to communicate. Again, the closest meaning of coordination provided by Webster (1983: 288) is being in "a common action, movement, or condition". It has little to do with the communication of content per se. Furthermore, Holtgraves' claim that "intersubjectivity is a state that is achieved to varying degrees through language" (127) may also be regarded as an exaggeration of both Rommetveit's own position and the facts of the matter. Rommetveit (1974:39) speaks instead of the expansion, modification, and increase of intersubjectivity through language, but language is always already assumed to be "nested on to only partially shared social realities".

The preceding excursus has been necessary because taking perspective rather than having perspective has been the dominant theme of research on perspective. Developmentally, existentially, and epistemologically, however, having one's own personal perspective as speaker is both prior to and more fundamental than perspective taking. Nor is having a personal perspective to be identified only with the egocentric perspective that is the defining feature of Piaget's preoperational stage (see Holtgraves 2002: 122). In fact, the prototypical motivation for initiating speech is to express one's own perspective.

Holtgraves' (2002) approach to perspective taking is explicitly from the point of view of the social psychologist. From the point of view of discourse analysis, however, perspective taking has not become a salient research theme. In fact, the only research on perspective referenced in the recent Handbook of discourse analysis (Schiffrin, Tannen, \& Hamilton 2001) is about the speaker's having a personal perspective (Ainsworth-Vaughn 2001: 457; see also Wilson 2001: 399).

The present research is a psycholinguistic investigation about having personal perspective. The concept is closely related to the dialogical, always under "dyadic control" 
and "intersubjectively endorsed" (Rommetveit 1990: 98). It is firmly ensconced in social interactionist theory, phenomenology, pragmatism, social psychology, and semiotics (Linell 1998: 40; see also Suleiman, O'Connell, \& Kowal 2002: 283). The logic is then that indicators of personal perspective can be found that essentially entail dialogicity (Bakhtin 1981: 314) and that meaning itself is indeed negotiated in terms of perspective, not pregiven or provided in advance, not inherent in linguistic structures (Suleiman et al. 2002: 297). Suleiman et al. also found personal perspective reflected in involvement/distancing, self-presentation, and political positioning as well as in defensiveness, momentary confusion, sense of social identity, ambivalence, loss of control, and anger (294).

Although personal perspective can be approached empirically with a variety of methods, investigation of the use of personal pronominals provides an obvious beginning point. Psycholinguistically, use of personal pronominals inevitably positions a speaker relative to ambient reality. Such an approach, in fact, began to develop in the last years of the previous century, ori-ginally conceptualized in terms other than personal perspective. Thus, Maitland and Wilson (1987) reported pronominal use in the service of speaker distancing/involvement in British politicians. Urban (1988) investigated the persuasive force of first-person plural pronominals in written discourse. De Fina (1995) distinguished pronominal use to signal three kinds of speaker involvement: Topical, personal, and social. Chilton and Schäffner (1997) studied how pronominals position speaker, audience, and others in social and political space. A review of this research tradition is to be found in Suleiman (1999).

These studies were typically carried out with a qualitative methodology, i.e., with an emphasis on the organization of local structure and the demonstration thereof through examples. To pursue the pronominal research further, Suleiman et al. (2002) have combined quantitative and qualitative methodologies, since they are, in fact, both needed complementarily in order to explain both sociocultural phenomena and local organization in discourse (see Linell 1998: 47).

Suleiman et al. also accepted Linell's (1998: 48) general description of personal perspective:

"Each thought or utterance views aspects of the world from some particular vantage-point, thus telling us (as recipients or analysts) something not only about the things talked about but also about the actor's background."

The general concept of personal perspective was intended to replace the variety of concepts used in the previous research, including: self (e.g., Goffman 1959), face (e.g., Goffman 1967), footing (e.g., Goffman 1981; see also Levinson 1983), frame (e.g., Schiffrin 1994), and positioning (e.g., van Langenhove \& Harré 1993; see also Harré 2001). Suleiman (2000) has presented a critical overview of these concepts, all of which fulfill only partially the generality and clarity provided by the concept of personal perspective.

Finally, Suleiman et al. (2002) reported in BBC TV HARDtalk interviews of Tim Sebastian with Shimon Perez and Edward Said, in addition to pronominals, a number of other indicators of personal perspective on the part of both interviewer and interviewees: turn-initial words, hesitations, questions, use of emphatic yes and no, personal reference utterances (e.g., I think), interjections, relative number of syllables spoken by interviewer and interviewee, and interruptions and overlaps.

In the following there is no assumption that pronominal usage is related to personal 
perspective in a one-to-one manner. Suleiman (2000: 42) comments that even the more specific concept of footing is revealed

"in a wide variety of linguistic and paralinguistic devices, such as code-switching, change from direct speech to reported speech, the use of pronouns, and possibly in terms of prosody and intonation change."

She thereby pinpoints a set of very complex relationships in need of further research. Hence, at the present stage of research, a determinate operationalization of personal perspective in interviews does not appear appropriate. The concept of personal perspective, in order to remain heuristic, must remain open to optional indicators that may or may not be present in a given corpus. For example, in the corpus to be introduced here, initial words at turns proved to be useless, simply because there was no notable preference for such indicators in the data. Such flexibility is suggested methodologically in Clayman and Heritage's (2002: 21 and 344) descriptions and examples of micro- and macro-analyses.

Political TV news interviews (see Clayman \& Heritage 2002) have been chosen for a number of reasons. According to Farr (1984: 182), it is of the very nature of interviews to elicit personal perspective since the interview constitutes "a technique for establishing or discovering that there are perspectives or viewpoints on events other than those of the person initiating the interview". Such interviews also engage serious, current issues in a relatively orderly and articulate fashion, because the interviews take place in the public forum. In addition, recordings of public interviews are typically of media quality and pose no problem of data collection, since they exclude the necessity for either unethical surreptitious recording or intrusive and disruptive recording.

Pronominal usage in the setting of TV news interviews should generally reflect personal perspective. More specifically, interviewers' efforts to elicit interviewees' perspective through questioning are typically couched in terms of second-person singular pronominals. Correspondingly, interviewees' responses are about their involvement with themselves, their activities, and/or their issues, typically in first-person singular pronominals. Further, interviewees who represent various groups generally express their identification with and responsibility for the group in first-person plural pronominals. Finally, a high density of third-person pronominals (singular and/or plural) reflects distancing on the part of both interviewer and interviewee from the issues or persons under discussion.

The relevance of an uneven proportion of syllables spoken by interviewer and interviewee springs from the very finality of the interview and the corresponding roles of interviewer and interviewee: Access to the personal perspective of the interviewee mandates shorter questions and longer answers. Research has shown that this proportion is roughly $25 \%$ of spoken syllables (or of speaking time) for the interviewer and correspondingly $75 \%$ for the interviewee (see Kowal, Barth, Egemann, Galusić, Kögel, Lippold, Pfeil, \& O'Connell 1998; Kowal \& O'Connell 1997; Kowal \& O'Connell 2002; O'Connell \& Kowal 1998; O'Connell, Kowal, \& Dill in press; Suleiman et al. 2002). Significant inflation of the interviewer's percentage indicates some change in the interaction in the interview.

Use of questions is, of course, typical for the interviewer. In fact, Clayman and Heritage (2002: 95 and 149) consider "the question-answer format" both constitutive and normative for the TV news interview. Questions on the part of the interviewee indicate a shift in the interviewee's role, from presentation of a personal perspective to inquiry into 
the interviewer's own perspective (see Suleiman et al. 2002). Use of a multitude of tag questions has been characterized as "talking like a lady" (Lakoff 1975: 8).

Relatively more syntactic well-formedness is to be expected of interviewers, since they do make use of written notes and do preplan their questions. Relative spontaneity is to be expected of interviewees (Kowal \& O'Connell 1997; O'Connell \& Kowal 1998), since preplanning for specific questions and use of notes are both excluded. Hence, relatively greater use of hesitations, emphatic yes and no, and personal reference utterances (e.g., I think) is also to be expected on the part of the interviewees.

Turn transitions have proven differentially characteristic of interviewers' and interviewees' perspectives (Kowal et al. 1998). Time restraints sometimes lead to more interruptions on the part of interviewers, whereas adversarial perspectives increase overlaps and interruptions on the part of both interviewers and interviewees. The turn-taking categories of Kowal et al. (1998: $285 \mathrm{ff}$.) were adopted for this research: Smooth transitions with or without pause, interruptions (successful or unsuccessful), and overlaps.

The linguistic performance measures corresponding to these concepts are analyzed quantitatively in terms of descriptive and inferential statistics in the results section below. Discussion of their qualitative contextualizations follows, in order to establish their interactional and perspectival relevance. Extralinguistic, nonverbal indicators of perspective (e.g., gestures) are clearly important in these settings, but cannot be systematically engaged in the present research.

\section{Methods}

Two interviews by Christiane Amanpour, conducted on CNN TV (both on September 8, 2000), were chosen as data base: With Ehud Barak and with Yasser Arafat. All the speakers are non-native speakers of English, although the interviewer is fluent, Barak adequate, and Arafat not fluent. Transcripts prepared by $\mathrm{CNN}$ staff members provided the initial data. From audio cassette recordings derived from the $\mathrm{CNN}$ video recordings, the transcripts were corrected. Changes were made only if two co-authors were in agreement. With corrections, the Barak interview was 2941 syl and the Arafat interview 1533 syl in length. Normalization of frequency counts for response measures (see Biber, Conrad, \& Reppen 1998: 263) was made in terms of an index of syllables per response measure. The following response measures were recorded and analyzed as in Suleiman et al. (2002): number of syllables produced by each speaker; occurrence of hesitations (repeats, false starts, and filled pauses); all pronominal usage, separately recorded by number (singular or plural) and person (first, second, or third); emphatic no and yes; types of turn transitions; number of questions and tag questions used; and personal reference utterances (I believe, I mean, I think, you know, you see).

\section{Results}

\subsection{Descriptive and inferential statistics}

In Table 1, the frequency counts of syllables for both interviews are presented along with their respective percentages. Also included are frequency and normalized index of 
hesitations (repeats, false starts, and filled pauses). The reader should note that, in the inferential statistics presented for the data of both Table 1 and Table 2, numerical differences for the raw frequency and for the normalized index are always in opposite directions: A high frequency corresponds to a low index and vice versa. In all cases, $d f=1$.

Table 1 shows that Amanpour spoke $28 \%$ of all syllables in the Barak interview. This finding is in complete accord with the

Table 1. Frequency (\#) and Percentage (\%) of Syllables (Syl); \# and Normalized Syllables per Response Measure Index (I) for Hesitations: Repeats (R), False Starts (FS), Filled Pauses FP), and All Hesitations for Interviewer (Christiane Amanpour, CA) and Interviewees (Ehud Barak, EB; Yasser Arafat, YA)

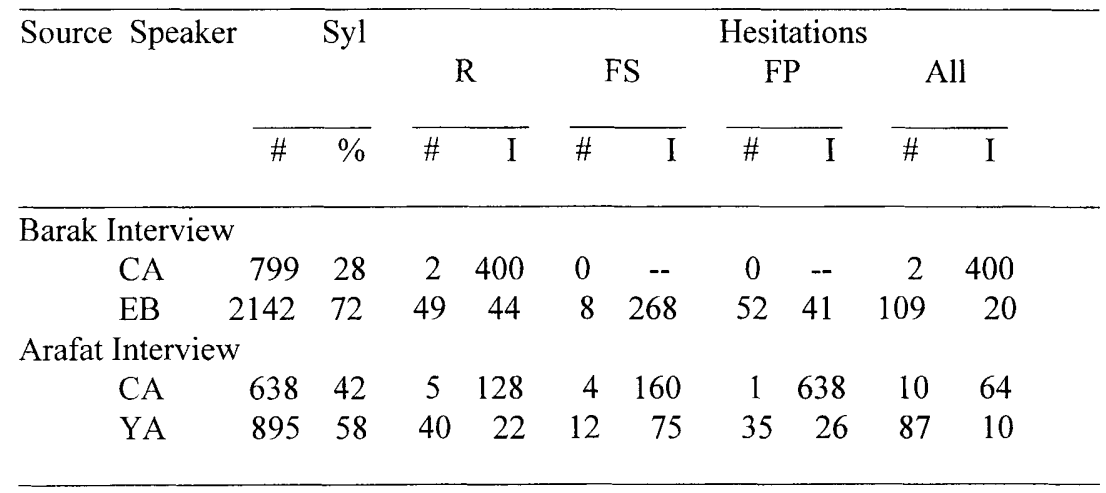

research literature. However, she spoke $42 \%$ of all syllables in the Arafat interview - a striking departure from the expected percentage. As expected, in her role as interviewer Amanpour used very few hesitations (12 altogether), but significantly more with Arafat than with Barak $(64<400 \mathrm{syl} /$ hesitation; $\chi 2=243.31, p<.001)$. More specifically, across her spoken performance with the two interviewees, there are significantly more repeats with Arafat than with Barak $(128<400$ syl/repeat; $\chi 2=140.12, p<.001)$.

With respect to the interviewees, although the difference was not significant, Arafat used proportionally more hesitations $(10<20$ syl/hesitations $)$ than Barak. But Arafat used significantly more repeats $(22<44 \mathrm{syl} /$ repeat; $\chi 2=7.34, p<.01)$ and significantly more false starts $(75<268$ syl/false start; $\chi 2=107.74, p<.001)$ than Barak.

In Table 2, frequency and normalized syllables per response measure index of pronominals, no, and yes for Amanpour, Barak, and Arafat are presented. Overall, the index for syllables per all pronominals is remarkably the same across all speakers (range $=9-12 \mathrm{syl} / \mathrm{all}$ pronominals).

As expected, in her role as interviewer Amanpour used first-person singular pronominals (1S) significantly less frequently than second-person pronominals (2SP) (20 $\left.<56 ; \chi^{2}=17.06, p<.001\right)$. But she used first-person singular pronominals (1S) significantly more frequently with Arafat than with Barak $\left(49<114\right.$ syl $\left./ 1 \mathrm{~S} ; \chi^{2}=25.92, p<.001\right)$.

True to his role as interviewee, Barak used significantly more first-person singular pronominals than second-person pronominals $(53>5 ; \chi 2=39.72, p<.001)$. In addition, he used first-person plural pronominals (1P) equally as often as first-person singular pronominals.

Arafat's pattern is entirely different. Instead, he used second-person pronominals 
almost exactly as often as he used first-person singular pronominals $(37 \approx 36)$, whereas he used first-person plural pronominals significantly less often than first-person singular pronominals $(8<36 ; \chi 2=17.82, p<.001)$. Arafat also used significantly less first-person plural pronominals than did Barak $\left(112>40 \mathrm{syl} / 1 \mathrm{P} ; \chi^{2}=34.10, p<.001\right)$ and used significantly more second-person pronominals than did Barak $\left(24<428 \mathrm{syl} / 2 \mathrm{SP} ; \chi^{2}=\right.$ $361.10, p<.001)$.

Table 2. Frequency (\#) and Normalized Syllables per Response Measure Index (I) for Interviewer (Christiane Amanpour, CA) and Interviewees (Ehud Barak, EB; Yasser Arafat, YA) for Pronominals: First-Person Singular (1S) and Plural (1P), Second Person Singular and Plural (2SP), Third Person Singular and Plural (3SP), It , and All; and for No and Yes

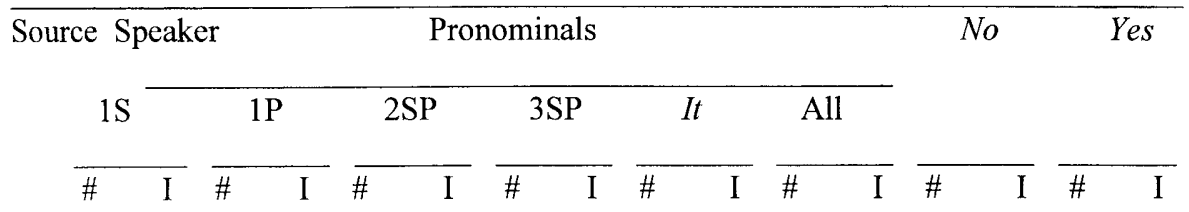

Barak Interview

$\begin{array}{lcccccccccccccccr}\text { CA } & 7 & 114 & 4 & 200 & 30 & 27 & 23 & 35 & 7 & 114 & 71 & 11 & 1 & 799 & 0 & -- \\ \text { EB } & 53 & 40 & 53 & 40 & 5 & 428 & 33 & 65 & 41 & 52 & 185 & 12 & 4 & 536 & 0 & -- \\ \begin{array}{l}\text { Arafat Interview } \\ \text { CA }\end{array} 13 & 49 & 2 & 319 & 26 & 25 & 11 & 58 & 3 & 213 & 55 & 12 & 5 & 128 & 1 & 638 \\ \text { YA } & 36 & 25 & 8 & 112 & 37 & 24 & 14 & 64 & 10 & 90 & 105 & 9 & 7 & 128 & 5 & 179\end{array}$

Finally, there are no significant findings for third- personal pronominals altogether or for $i t$ in isolation.

No was used significantly more often by Amanpour with Arafat than with Barak $(128<799 \mathrm{syl} / n o ; \chi 2=486.62, p<.001)$, and Arafat himself used no significantly more than did Barak $(128<536 \mathrm{syl} / n o ; \chi 2=250.70, p<.001)$. Emphatic yes did not occur in the Barak interview; in the Arafat interview, he used yes significantly more often than Amanpour $(179<638 \mathrm{syl} /$ yes; $\chi 2=257.06, p<.001)$.

In Table 3 , the frequencies and percentages of the various types of turn transitions from one speaker to another are shown. It should be noted that, even though the Barak interview is almost twice as long as the Arafat interview in syllables $(2941>1533)$, the number of turns in the Barak interview (18 for Barak and 16 for Amanpour) is half that of the Arafat interview ( 36 for Arafat and 35 for Amanpour). Transitions from interviewee to interviewer were $92 \%$ smooth with or without a pause $(89 \%$ with Barak; $94 \%$ with Arafat). Such high percentages have been found typical of media interviews (see, e.g., Kowal et al. 1998). Transitions from Amanpour to Barak were intermediate in this regard $(72 \%)$, whereas only $53 \%$ of the transitions from Amanpour to Arafat were smooth. These 
latter two findings are more characteristic of the findings of Suleiman et al. (2002) for BBC HARDtalk interviews of Tim Sebastian. More than $40 \%$ of the transitions from Amanpour to Arafat involved either overlapping Table 3. Frequencies (\#) and Percentages (\%) of Turn Transitions: Smooth with (S+P) and without (S-P) Pause, Overlaps (O), and Successful (SI) and Unsuccessful (UI) Interruptions for Amanpour from Amanpour to Barak (CA --> EB), from Amanpour to Arafat (CA --> YA), from Barak to Amanpour (EB --> CA), from Arafat to Amanpour (YA --> AC), and All Turn Transitions

\begin{tabular}{|c|c|c|c|c|c|c|c|c|c|c|}
\hline \multirow[t]{4}{*}{ Type } & \multicolumn{8}{|c|}{ Direction of Turn Transition } & \multicolumn{2}{|c|}{ All } \\
\hline & \multicolumn{4}{|c|}{--> Interviewee } & \multicolumn{4}{|c|}{--> Interviewer } & \multirow[b]{3}{*}{ \# } & \multirow[b]{3}{*}{$\%$} \\
\hline & \multirow{2}{*}{$\begin{array}{l}\mathrm{CA}--> \\
\#\end{array}$} & \multirow{2}{*}{$\frac{\mathrm{EB}}{\%}$} & \multicolumn{2}{|c|}{ CA $-->$ YA } & \multicolumn{2}{|c|}{$\mathrm{EB}-->\mathrm{CA}$} & \multicolumn{2}{|c|}{ YA $-->C A$} & & \\
\hline & & & \# & $\%$ & \# & $\%$ & \# & $\%$ & & \\
\hline $\mathrm{S}+\mathrm{P}$ & 9 & 50 & 13 & 36 & 11 & 69 & 24 & 69 & 57 & 54 \\
\hline S-P & 4 & 22 & 6 & 17 & 4 & 25 & 7 & 20 & 21 & 20 \\
\hline $\mathrm{O}$ & 3 & 17 & 8 & 22 & 0 & -- & 3 & 9 & 14 & 13 \\
\hline SI & 0 & -- & 7 & 19 & 1 & 6 & 1 & 3 & 9 & 9 \\
\hline UI & 2 & 11 & 2 & 6 & 0 & -- & 0 & -- & 4 & 4 \\
\hline All & 18 & 100 & 36 & 100 & 16 & 100 & 35 & 101 & 105 & 100 \\
\hline
\end{tabular}

(22\%) or successful interruption on his part (19\%). In contrast,

the corresponding percentages of transitions from Amanpour to Barak were 17\% overlaps and no successful interruptions, or less than half the corresponding percentage for Arafat $(17 \%<40 \%)$. There was no back channeling in these interviews on the part of either interviewer or interviewees.

Only 12 personal reference utterances occurred in the entire corpus: You know (1) on the part of Amanpour in the Arafat interview and I believe (8), I think (2), and you know (1) on the part of Barak.

With respect to questions, Amanpour used 13 questions in her 16 turns with Barak, whereas Barak used none in his 18 turns. With Arafat, Amanpour used only 12 questions in her 35 turns, whereas Arafat used 11 questions in his 36 turns with her. Amanpour's two tag questions in the Arafat interview were the only tag questions in the entire corpus.

\subsection{A perspectival recasting of results}

The significant findings detailed thus far assume genuine psychological meaning only by being contextualized within the personal perspectives of the three interlocutors. This section accordingly recasts the results as comparisons of three sets of perspectives: (1) the interviewer's and the interviewees'; (2) Barak's and Arafat's; and (3) Amanpour's in each of the two interviews. 
(1) The Interviewer's and the Interviewees' Perspectives. The interviewer's professional role is to foster the expression of the interviewee's perspective for an audience. In turn, this requires that the interviewer's own perspective be de-emphasized. This requirement implies an adequate level of skill, experience, and preparation on the part of the interviewer. A number of our findings reflect this dynamic in Amanpour: The obvious fact that the majority of the syllables spoken are those of interviewees; her use of fewer hesitations; her preference for second-person pronominals over first-person pronominals, both singular and plural; and her use of mostly smooth turn transitions.

As regards the interviewees, their common perspective as interviewees is reflected in only two measures: The large number of syllables spoken and the large number of hesitations.

(2) Barak's and Arafat's Perspectives. In addition to their perspectives as interviewees, Barak and Arafat also brought very idiosyncratic perspectives to their interviews. These differences are reflected in some of our findings: Barak's use of a higher proportion of syllables than Arafat; his use of longer and fewer turns; his use of fewer hesitations of all types; his preference for first-person plural over second-person pronominals; his lack of successful interruptions; correspondingly, his use of fewer overlapping syllables; and finally his non-use of questions. In these respects, Barak showed himself to be the standard, stereotypic interviewee. Arafat, on the other hand, departed dramatically from this pattern in a number of ways: His representation of his people was not strongly reflected in his use of first-person plural pronominals; instead, he spoke largely in his own name even when he referred to "my people" insofar as he used a great many first-person singular pronominals; his use of emphatic no and yes was more frequent than Barak's and in four instances fulfills Clayman and Heritage's (2002: 252) description of "minimal responses. . . indicative of tacit resistance to the broader agenda of the question"; he used many successful interruptions; and he used nearly as many questions as were used by Amanpour.

(3) Amanpour's perspectives in each of the two interviews. The pertinent differences in perspective between the two TV news interviews can best be characterized as Amanpour's departures from typical professional perspective in the Arafat interview: Almost half of the syllables spoken were hers; in all hesitation categories, she used more than with Barak; and she used more first-person singular pronominals with Arafat. What is, however, noteworthy and quite remarkable is the fact that, despite an extraordinarily agonistic setting in the Arafat interview, Amanpour manifested the same predominantly smooth turn transitions as in the Barak interview.

\section{Discussion}

\subsection{Comparisons with Suleiman et al. (2002)}

The present research confirms Suleiman et al.'s findings in many resepcts, particularly with regard to hesitation phenomena: Use of hesitations was consistently lower for interviewers than for interviewees. In other words, the numerous hesitations of the interviewees reflect their situation of relative spontaneity and orality, rather than the interviewers' situation of relative literacy characterized by preparation in the written mode. Interviewees' hesitation was also contributed to by their non-native English and in the case of Arafat, presumably 
by the agonistic setting. In any event, his speech was the most hesitant of all speakers across both studies.

Both Sebastian/Said in Suleiman et al. and Amanpour/Barak in the present research manifest a proportionate use of syllables characteristic of TV news interviews in the archival literature. But both Sebastian/Peres in Suleiman et al. and Amanpour/Arafat in the present research depart notably from these expectations. Both departures reflect a shift in a mutual dynamic: The interviewer adversarially expressed more of his or her personal perspective and dimished thereby the effort to elicit expressions of the interviewee's personal perspective; meanwhile, the interviewee struggled, also adversarially, to pursue his personal perspective.

The characteristics of turn-taking provide another comparison with Suleiman et al. Amanpour used $94 \%$ smooth turn transitions with Barak and $89 \%$ with Arafat, again quite in accord with expectations from the archival literature. On the other hand, Sebastian used only $57 \%$ smooth turn transitions with Peres and only $36 \%$ with Said. In this case, the deviation is a function of the harsh, interruptive style that defines Sebastian's so called HARDtalk series. Sebastian's interviewees followed his lead and, in accord with the HARDtalk style, used fewer smooth turn transitions (Peres $48 \%$ and Said $51 \%$ ). Arafat's use of fewer smooth transitions (53\%), however, is far more a matter of an extremely adversarial approach to the interviewer. In such cases, the effort to express one's personal perspective devolves into a turf war.

Pronominal usage is also different in Suleiman et al. and the present research. Amanpour used far more first-person singular and plural pronominals than Sebastian; the mean of Sebastian's four indices across his two interviews is 531 syl/1SP, whereas the corresponding mean for Amanpour is 170/1SP. Amanpour was clearly expressing her own personal perspective very strongly for one in the interview role.

\subsection{Agonistic perspective in interviews}

As was also the case in Suleiman et al., the issues engaged in these interviews were all current, earnest, and controversial. The Arafat interview, however, involved something quite different from the programmatic HARDtalk of Tim Sebastian. In the Arafat interview, the agonistic perspective appears to be dominantly on the part of the interviewee, and Amanpour's agonistic role appears to be instead reactive and defensive. Indicators of Arafat's agonistic stance include his use of both harsh diction and of more first-person singular and second-person pronominals than any of the other speakers in the present study:

\section{Example 1}

YA first of all I respect what II had mentioned and promised my people my nation my religions the Christianity and the Islam and I am not to betray them you have to remember with whom you are speaking you are speaking with Yasser Arafat

As the example eloquently shows, the $I / y o u$ confrontation manifests a highly personal perspective.

Arafat's hesitations were also more frequent than were those of any of the other speakers in the present study and in Suleiman et al. The numerosity of Arafat's hesitations is clearly related to his level of frustration with the interviewer as well as to his lack of skill 
with the English language and his personal defensiveness:

Example 2

YA in spite of what you are mentioning I am not in uh uh uh I am not a situation to ask your advices I have uh uh many advisors whom I am respecting their advises and and following their advices not for your advice

Typical media standards would categorize the diction of this $1 / y o u$ confrontation as impolite antagonism.

Arafat's agonistic perspective with regard to Amanpour is also expressed in his unusual use of questions and turn transitions. Almost a third (11/36; Amanpour asked only 12 herself) of Arafat's turns involved questions - proportionally more than any of the other interviewees' turns in the present research and in Suleiman et al. He also spoke proportionally more overlapping syllables and interrupted (successfully [7] and unsuccessfully [2]) proportionally more than any of the other interviewees in both studies. In Example 3, the leitmotiv of betrayal, both Arafat's ("I can't betray my people.") and Amanpour's ("Would you betray your people?"), which is a focal argument throughout most of the interview, is emphasized:

\section{Example 3}

\begin{tabular}{|c|c|}
\hline YA & would you betray your people \\
\hline $\mathbf{C A}$ & but \\
\hline YA & your people \\
\hline CA & I'm not in the same position you are \\
\hline YA & $\begin{array}{l}\text { are in your duty in your position are you ready to } \\
\text { betray your people }\end{array}$ \\
\hline $\mathbf{C A}$ & $\begin{array}{l}\text { well then the question then } \\
\text { is the people want a future }\end{array}$ \\
\hline YA & $\begin{array}{c}\text { you } \\
\text { and obviously }\end{array}$ \\
\hline $\mathbf{C A}$ & yeah \\
\hline YA & do you accept to betray your \\
\hline $\mathbf{C A}$ & but I don't have people to betray \\
\hline
\end{tabular}

Such a sequence of questions on the part of an interviewee is extraordinarily unusual. Given the character of this interaction, it is hardly surprising that the interview terminated soon thereafter with the peremptory dismissal of the interviewer:

YA you are forgetting everything now it is enough

Amanpour's method of coping with Arafat's aggressive attitude is also of interest. Arafat pressured her into a defensive position in which she could no longer maintain a dispassionate background perspective: Her speech became more hesitant; she began to use more first-person singular pronominals; she was able to ask fewer questions; and she used emphatic no more frequently. It is all the more impressive that, under such pressure, she 
was still able to maintain a professional stance by her predominant use of smooth turn transitions.

But this is only half the story: An agonistic perspective is always both reciprocal and dialogical. The content and harsh diction of Amanpour's questions in Example 5 preceded and kindled Arafat's agonism, especially in view of the fact that he had just been publicly blamed by President Clinton for the failure of the Camp David meeting:

\section{Example 5}

CA ... do you think that you can get even more out of him that you can outmaneuver him outlast him politically is that why you're waiting to get more out of an Israeli prime minister

YA

first of all I'm not asking for the moon I'm asking what has been signed what has been agreed upon to be implemented accurately and honestly not more not less are you against

CA

YA this

CA when prime minister when

are you against this

let me ask you this though when Prime Minister Netanyahu was prime minister you used to say the same thing I'm not asking for the moon

This is where the battle really begins. The sullenness displayed by Arafat in his preceding abrupt yes and no answers was expressed subtly from the beginning and here is made quite explicit. The gloves are off. Immediately after the interview, Amanpour characterized Arafat as very feisty, but he was not alone in this characteristic. There is definitely something far beyond HARDtalk in Amanpour's aggressiveness in this interview.

The most basic difference between the two interviews analyzed here is the personal perspective elicited by the agonistic stance of both interviewer and interviewee in the Amanpour/Arafat interview, but not in the Amanpour/Barak interview. An agonistic stance always emphasizes personal perspective and diminishes perspective taking. In particular, the role of the interviewer in eliciting the perspective of the interviewee is thereby compromised: Attempting to fulfill the finality of the interview situation on the part of the interviewer by ferreting out the perspective of the interviewee is well nigh impossible when the interviewee takes over the questioning and demands answers from the interviewer instead of answering her questions. Nonetheless, the agonistic setting does paradoxically arrive at the perspective of the interviewee by another route, precisely through the agonistic show of perspective on the part of the interviewee. The fact that CNN televized the Arafat interview is itself evidence that the producers realized that it was a worthwhile journalistic presentation of Arafat's perspective, even though it accomplished that goal in an unconventional - and generally unacceptable - way. Despite the altercation, the Arafat interview was a good interview.

Another agonistic pairing of Amanpour and Arafat in a telephone interview a year and a half later is reported in a Berlin newspaper, Der Tagesspiegel (March 31, 2002: 5), after the Israeli army had attacked Arafat's headquarters in Ramallah:

Arafat accused the CNN correspondent Christiane Amanpour of partisanship in favor of the Israelis. He interrupted the journalist with: "You have to be careful when you speak with General Yasser Arafat. With that kind of question, you disguise terrorist activities of the Israeli occupation force and Israeli criminality. Be fair. Thank you. Goodbye". (Our translation back into English; see also 
Example 5 above)

And thereupon, Arafat hung up.

This is certainly not a conventional phone interview, but it remains excellent journalism insofar as the finality of the interview is fulfilled. Arafat's own personal perspective is dramatically displayed! However, Amanpour's role here could harldy be described as perspective taking; she was, in fact, unable to pursue the perspective of the interviewee in her questioning.

\section{Concluding comments}

Despite the complexity and individuality of the concept of personal perspective, reliable indicators of personal perspective have been found in the TV news interviews analyzed in the present research. This is in sharp contrast to Garrod and Pickering's (1999: 10) contention that "the language of dialogue is disorderly compared to the straightforward grammatical sentences of monologue". Even the non-native, angry, and inarticulate speech of Arafat remains dialogically lawful precisely insofar as it serves the function of revealing his personal perspective. And the aggressiveness of Amanpour contributes therunto. The empirical method of isolating indicators of perspective involves quantitative analysis of global effects and is supplemented by qualitative examples to demonstrate local organization. In this respect, the present findings confirm the approach of Suleiman et al. (2002).

Since dialogicality is essentially dependent on momentary reciprocal intersubjectivity, it can be shifted at a moment's notice. This is exactly what happens to Amanpour's perspective under the onslaught of Arafat's agonistic questions. Ordinarily the interviewer's personal perspective is backgrounded (as in the Barak interview), but in this case it was not. In this sense, Arafat took over the interview, but not without an invitation. Both were feisty.

Rommetveit's (1990: 98) contention that perspective is always under "dyadic control" is endorsed by these findings. And they confirm both "the reciprocity of perspectives" and "the interactional character of perspective-taking" of Graumann (1989: 99). Both having a perspective and taking a perspective must be investigated dialogically.

\section{References}

Ainsworth-Vaughn, N. (2001) The discourse of medical encounters. In D. Schiffrin, D. Tannen, \& H. Hamilton (eds.), The handbook of discourse analysis. Malden, MA: Blackwell, pp. 453-469.

Bakhtin, M. (1981) The dialogical imagination: Four essays (trans. C. Emerson \& M. Holquist; ed. M. Holquist). Austin, TX: Texas University Press.

Biber, D., S. Conrad, \& R. Reppen (1998) Corpus linguistics: Investigating language structure and use. Cambridge: Cambridge University Press.

Chilton, P., \& C. Schäffner (1997) Discourse and politics. In T.A. van Dijk (ed.), Discourse as social interaction. Discourse studies: A multidisciplinary introduction (Vol. 2). London: Sage, pp. 206-230. 
Clark, H.H. (1994) Discourse in production. In M.A. Gernsbacher (ed.), Handbook of Psycholinguistics. San Diego, CA: Academic Press, pp. 985-1021.

Clark, H.H. (1996) Using language. Cambridge: Cambridge University Press.

Clayman, S., \& J. Heritage (2002) The news interview: Journalists and public figures on the air. Cambridge: Cambridge University Press.

De Fina, A. (1995) Pronominal choice, identity, and solidarity in political discourse. Text 15: 379-410.

Der Tagesspiegel (2002) Zurechtweisung vom General. (March 31, 2002: 5).

Farr, R.M. (1984) Interviewing: An introduction to the social psychology of the interview. In C.I. Cooper \& P. Makin (eds.), Psychology for managers (2nd ed.). London: Macmillan, pp. 176-194.

Garrod, S., \& M.J. Pickering (1999) Issues in language processing. In S. Garrod \& M.J. Pickering (eds.), Language processing. Hove, East Sussex, UK: Psychology Press, pp. 1-11.

Goffman, E. (1959) The presentation of self in everyday life. New York: Anchor.

Goffman, E. (1967) Interaction ritual. New York: Anchor.

Goffman, E. (1981) Forms of talk. Philadelphia, PA: University of Pennsylvania Press.

Graumann, C. (1989) Perspective setting and taking in verbal interaction. In R. Dietrich \& C.F. Graumann (eds.), Language processing in social context. Amsterdam: North Holland, pp. 95-122.

Harré, R. (2001) The discursive turn in social psychology. In D. Schiffrin, D. Tannen, \& H. Hamilton (eds.), The handbook of discourse analysis. Malden, MA: Blackwell, pp. 608-706.

Holtgraves, T.M. (2002) Language as social action: Social psychology and language use. Mahwah, NJ: Erlbaum.

James, W. (1890/1983) The principles of psychology. Cambridge, MA: Harvard University Press.

Kowal, S., H.-C. Barth, H. Egemann, G. Gasulić, C. Kögel, N. Lippold, A. Pfeil, \& D.C. O'Connell (1998) Unterbrechungen in Medieninterviews: Geschlechtstypisches Gesprächsverhalten? Germanistische Linguistik 139-140: 279-299.

Kowal, S., \& D.C. O'Connell (1997) Theoretical ideals and their violation: Princess Diana and Martin Bashir in the BBC interview. Pragmatics 7: 309-323.

Kowal, S., \& D. C.O'Connell (2002) Interjektionen im Gespräch. Zeitschrift für Semiotik 24: xx-xx.

Lakoff, R. (1975) Language and woman's place. New York: Harper \& Row.

Levinson, S. (1983) Pragmatics. Cambridge: Cambridge University Press.

Linell, P. (1998) Approaching dialogue: Talk, interaction and contexts in dialogical perspectives. Amsterdam: John Benjamins.

Maitland, K., \& G. Wilson (1987) Ideological conflict and pronominal resolution. Journal of Pragmatics 11: 495-512.

O'Connell, D.C., \& S. Kowal (1998) Orality and literacy in public discourse: An interview of Hannah Arendt. Journal of Pragmatics 30: 543-564. 
O'Connell, D.C., S. Kowal, \& E.J. Dill III (in press) A Dialogical Approach to TV News Interviews. Journal of Pragmatics 34.

Rommetveit, R. (1974) On message structure: A framework for the study of language and communication. New York: Wiley.

Rommetveit, R. (1990) On axiomatic features of a dialogical approach to language and mind. In I. Markovà \& K. Foppa (eds.), The dynamics of dialogue. New York: Springer-Verlag, pp. 83-104.

Schiffrin, D. (1994) Approaches to discourse. Oxford: Blackwell.

Schiffrin, D., D. Tannen, \& H. Hamilton (eds.) (2001) The handbook of discourse analysis. Malden, MA: Blackwell.

Suleiman, C. (1999) Pronouns and self presentation in public discourse: Yasser Arafat as case study. In Yasir Suleiman (ed.), Language and society in the Middle East and North Africa: Studies in variation and identity. London: Curzon, pp. 104-121.

Suleiman, C. (2000) Pronoun use in television interviews: Social interaction and the Middle East peace process. Unpublished doctoral dissertation. Georgetown University, Washington, DC.

Suleiman, C., D.C. O'Connell, \& S. Kowal (2002) "If you and I, if we, in this later day, lose that sacred fire. .."; Perspective in political interviews. Journal of Psycholinguistic Research 31: 281-299.

Urban, G. (1988) The pronominal pragmatics of nuclear war discourse. Multilingua 7: 67-93.

van Langenhove, L., \& R. Harré (1993) Positioning and autobiography: Telling your life. In N. Coupland \& J. Nussbaum (eds.), Discourse and life-span development (Vol. 4). Newbury Park, CA: Sage, pp. 81-89.

Webster's ninth new collegiate dictionary. (1983) Springfield, MA: A Meriam-Webster.

Wilson, J. (2001) Political discourse. In D. Schiffrin, D. Tannen, \& H. Hamilton (eds.), The handbook of discourse analysis. Malden, MA: Blackwell, pp. 398-415. 